\title{
Formação de professores e as normativas curriculares em educação física
}

\author{
Marta Genú Soares ${ }^{\mathrm{a}, *} \mathbb{B}$, Meriane Conceição Paiva Abreu ${ }^{\mathrm{b}}{ }^{\circ}$, Emerson Duarte Monte ${ }^{\mathrm{a}}$
}

Palavras Chave:

Formação de

Professores;

Currículo;

Legislação;

Educação Física.

\begin{abstract}
RESUMO
O objetivo do presente texto é analisar a formação de professores, especialmente no campo da educação física. Problematiza o ordenamento legal para a formação de professores, que envida organização normativa para a formação em Educação Física. Metodologicamente realiza pesquisa bibliográfica e adota o método crítico-dialético para compreender a concepção de formação em Educação Física, frente às normativas curriculares, que orientam as agências formadoras no Brasil. Conclui que o ordenamento legal obstaculiza a formação ampla e única em educação física, pela separação entre os cursos, pela geração de um habitus produtivus, que busca a submissão do trabalho docente à lógica do capital, e o descompromisso com a profissionalidade docente.
\end{abstract}

\section{Keywords:}

Teacher training;

Curriculum;

Legislation;

Physical Education.

\begin{abstract}
The aim of this paper is to analyze the training of teachers, especially in the field of physical education. It problematizes the legal ordering for the formation of teachers, which sends normative organization for the formation in Physical Education. Methodologically it conducts bibliographic research and adopts the critical-dialectical method to understand the conception of formation in Physical Education, in face of the curricular norms, that guide the formation agencies in Brazil. It concludes that the legal system hinders the broad and unique formation in physical education, by the separation between the courses, by the generation of a productive habitus, which seeks the submission of the teaching work to the logic of capital, and the lack of commitment to the teaching professionalism.
\end{abstract}

\section{RESUMEN}

El objetivo de este trabajo es analizar la formación del profesorado, especialmente en el campo de la educación física. Problematiza el ordenamiento legal para la formación del profesorado, que envía una organización normativa para la formación en Educación Física. Metodológicamente realiza investigaciones bibliográficas y adopta el método crítico-dialéctico para comprender la concepción de la formación en Educación Física, frente a las normas curriculares, que guían a las agencias de formación en Brasil. Concluye que el sistema legal dificulta la formación amplia y única en educación física, por la separación entre los cursos, por la generación de un habitus productivo, que busca la sumisión del trabajo docente a la lógica del capital, y la falta de compromiso a la profesionalidad docente.

\footnotetext{
a Universidade do Estado do Pará, Departamento de Artes Corporais, PA, Brasil.

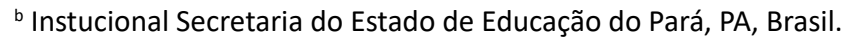

\section{*Autor correspondente:}

Marta Genú Soares

E-mail: martagenu@gmail.com 


\section{INTRODUÇÃO}

Ser professor é a condição do fazer com o outro no contexto social, do exercício docente na singularidade cultural, e que é ato reflexivo em contraponto com a teoria e a ciência (FREIRE; SHOR, 1986). A atividade de ensinar requer capacitação, responsabilidade política, competência técnica e militância crítica (GENÚ, 2016). Portanto, apreciar a formação de professores pressupõe apreender conceitos que perpassam pela concepção de sociedade, de formação humana, de educação e de intervenção docente para a transformação social pautada na equidade social, nos direitos humanos e nas condições mínimas de vida.

Para analisar a formação de professores ${ }^{1}$, especialmente no campo da educação física, o texto problematiza seu ordenamento legal, avaliando o estágioatual da discussãosobreas Diretrizes Curriculares Nacionais (DCN) para a formação em educação física, seus fundamentos teórico-metodológicos, com apontamentos para as possibilidades e superações das limitações envidadas pelas normatizações que orientam as agências formadoras no Brasil.

A fim de alcançar o objetivo proposto, metodologicamente o texto parte de um sentido de formação - e de formação em educação física -, que defende, pautado na literatura sobre o tema e, assim fundamentado, analisa o material legal histórico da formação em educação física, para finalmente, avaliar e apontar os desafios a enfrentar pelo campo da educação física. Esse movimento de análise é atendido pelo método crítico-dialético, em autores como Gamboa (2013); Triviños (2012), que subsidiam a argumentação teórico-metodológica, ao apontar a necessidade do aparato estrutural e lógico de um método, pelo qual se utiliza o processo histórico, para analisar a dinâmica contraditória, complexa e real do movimento da temática proposta, abrigando ainda, os sentidos de ser humano e sociedade que estão em jogo. Para realizar o tratamento dos dados, utiliza a técnica de análise de conteúdo, em Bardin (2011).

\section{A FORMAÇÃO EM PAUTA}

Pensar sobre formação de professor é ter claro que "em meio a complexidade que envolve a educação, em especial os sistemas públicos de ensino e a escola dos oprimidos, a mercê de políticas internacionalizadas e da doutrinação dos opressores, é preciso ousar" (ABREU, 2017, p. 11), no sentido de fortalecer-se e se munir, com a classe

1 A temática sobre a formação em educação física, a partir do ordenamento legal é fruto de debates ocorridos no grupo de pesquisa Ressignificar - experiências inovadoras na formação de professores e prática pedagógica em educação física, da Universidade do Estado do Pará (UEPA). de professores ${ }^{2}$, em grupos orgânicos ${ }^{3}$, por meio de formação-apropriação das condições de oferecimento da educação e das amarras que a conduzem legal e politicamente, entrelaçadas por grupos de concepções de mundo e sociedade divergentes.

Para tal, o estudo comunga com a acepção de formação de Freire (2011), para o qual esta deve gerar condições para que o sujeito se compreenda vinculado a sua história, a sua formação, como protagonista e como ser em processo; consciente, portanto, de seu inacabamento possa agir de maneira a ser mais; uma formação para a libertação.

Nesse sentido, essa formação não pode descuidar do rigor metodológico, mais ainda, possibilitar referencial teórico e conceitual que permita prover o sujeito de condições capazes de compreender sua situação real de formação, as concepções que a permeiam, para que ele mesmo se veja partícipe desse processo e conscientemente, aja como sujeito que é, mas que muitas vezes, é obstaculizado, pela própria formação e sua significação que o atingem como se este fosse "tábula rasa" (FREIRE, 2011).

Essa formação requer uma profissionalidade docente, que de acordo com Roldão (2005), caracteriza a profissão de professor, social e historicamente produzida e distinguível de outras profissões. A partir dos estudos de Giméno Sacristán, Claude Dubar e Antônio Nóvoa, a Roldão (2005) aponta quatro características, que perpassam as análises dos autores e que são relevantes para o conceito de profissionalidade, como: a especificidade da função; o saber específico; o poder de decisão; a pertença a um corpo coletivo (Ibid). É relevante lembrar que no percurso da profissionalidade, há forças estruturais das agências políticas do governo, materializadas nas políticas curriculares, de formação, na dependência organizativa de seu trabalho, que influenciam e condicionam a profissionalidade, neste caso, a docente, ou seja, há uma profissionalidade relativamente autônoma.

\footnotetext{
2 A compreensão de classe de professores no texto se alinha nos fundamentos da formação de professores e do trabalho docente, ou seja, são os sujeitos com formação na docência e que têm no trabalho docente, como processo relacional, real, complexo e histórico e como princípio, o desenvolvimento de uma consciência de classe docente, educativa, formativa; têm compreensão de sua situação profissional, dos condicionantes, buscam analisá-la e transformá-la. Isso significa que não bastam a formação e trabalho do professor, mas um profundo conhecimento da docência, da educação, dos condicionantes legais, conceituais, da sua posição no conjunto do campo do poder, de seu potencial consciente e mobilizador frente à sociedade capitalista.

3 Sob a acepção de intelectuais orgânicos de Antônio Gramsci, o texto considera grupos orgânicos, aqueles que compreendem e analisam sua especificidade e suas condições de inserção político-sociais, engajando-se nas relações sociais e conseguindo desenvolver seu potencial político.
} 
A profissionalidade na docência, faz-se por meio de uma formação inicial, com características específicas à docência, nas licenciaturas; da formação continuada, que dialoga com o trabalho do professor; e como categorias que constituem o tecido social, de modo articulado aos fenômenos da realidade concreta, construindo-se nas relações. Pensar a educação, a formação, o trabalho do professor, não pode ser papel de setores e/ou grupos alheios ao âmbito educativo ou à formação que especifica a profissionalidade docente, nem pode servir para atender aos interesses da ordem internacional e de modelos estrangeiros, como os envidados pelo Banco Mundial.

Pensar uma outra profissionalidade, mais autônoma, portanto, necessita considerar uma formação legal, mas a partir de uma construção coletiva dos reais conhecedores da docência: os professores. São esses agentes que estão desenvolvendo o trabalho de ensinoaprendizagem, em diferentes espaços educativos, com licença oficial para tal, em situações concretas, complexas e contraditórias e, que precisam ocupar os espaços de decisão, conscientes de sua identidade de sujeito com capital ${ }^{4}$ profissional específico. Esse é também um processo formativo para os docentes; têm significado, como aponta Freire (1996) em sua perspectiva formativa de autonomia.

Essa postura requer militância organizativa e significativa pela comunidade de professores, para compreender e superar a responsabilização e descrédito da educação, da formação e do trabalho docente, emanadas pelas organizações multilaterais, que estrategicamente têm disputado, pelo uso de desvios discursivos e ideológicos em busca do consenso em seus projetos, à direção da educação, como apontam Evangelista e Triches (2015).

\section{DECRETOS, RESOLUÇÕES E DIRETRIZES PARA A FORMAÇÃO}

Em Roldão (2005), observa-se que o currículo é importante quando se trata de profissionalidade docente, pois ele perpassa por aquilo que o professor ensina, tendo em vista sua relevância social para determinado contexto e época (ROLDÃO, 2000 apud ROLDÃO 2005) e, está vinculado ao elemento de poder de decisão do professor, como constituinte de sua profissionalidade.

$4 \mathrm{Na}$ interpretação em Bourdieu, capital pode ser considerado como uma forma de distinção de posições em determinado campo específico ou de classes sociais de poder. Materializa-se na posse, no monopólio de bens simbólicos e/ou materiais. Cf: BOURDIEU, Pierre. A distinção: crítica social do julgamento. Tradução Daniela Kern; Guilherme J. F. Teixeira. São Paulo: EDUSP; Parto Porto Alegre: Zouk, 2007.
Para isso, o currículo, sob um viés freireano, deve superar a hierarquia das disciplinas curriculares, a fragmentação do conhecimento e fazer frente ao poderio de políticas currículo-formativas distantes e destoantes da realidade e da constituição do sujeito de direito da experiência formativa ampliada.

$\mathrm{Na} E F$, esse tipo de currículo para a libertação e, consequentemente, a formação e a profissionalidade nesse processo, mostram-se em desenvolvimento de luta e resistência, pois nesse campo de conhecimento, pois nesse campo de conhecimento, não há apenas pressão das estruturas oficiais quanto ao aspecto currículoformativo, mas embates entre os próprios agentes desse campo por projetos de educação física diferenciados.

O tempo histórico deixa as marcas ideopolíticas na construção da formação em Educação Física (EF) no Brasil. O percurso da base legal sobre a formação é demarcado por concepções que atendem aos interesses da política econômica e do poderio ditador, que controla a sociedade, vilipendiando os estudiosos e pesquisadores desse campo ${ }^{5}$.

O decreto-lei no 1212/39 orientou a formação em EF no Brasil e criou Escola Nacional de Educação Física e Desportos, na então Universidade do Brasil/RJ, definindo a formação de pessoal técnico em educação física e desporto. Portanto, já se anunciava como capital simbólico, a divisão entre EF e desporto, caracterizando subáreas fragmentadas e/ou específicas, indicando claramente a formação em cinco cursos: a) curso superior de educação física; b) curso normal de educação física; c) curso de técnica desportiva; d) curso de treinamento e massagem; e) curso de medicina da educação física e dos desportos (BRASIL, 1939, p. 01).

Por meio do Decreto-Lei no 8270/45, a formação tem elevada a carga horária das disciplinas e o curso passa a ter três anos. O Parecer 298/62 traz ao curso superior de $E F$ e ao de técnico desportivo, a obrigatoriedade das matérias pedagógicas nos currículos, e esses ordenamentos, precedem a Resolução no 69/69, de 06 de novembro de 1969, que não anuncia concepção de $\mathrm{EF}$, mas define o conjunto de conhecimentos e o currículo mínimo sendo constituído.

5 Sobre o percurso histórico-curricular da educação física, cf: Abreu, 2016. Praxiologia em Bourdieu: análise entre o campo científico e o currículo da educação física. Dissertação (Mestrado em Educação), Belém: UEPA, 2016. AZEVEDO, Ângela Celeste Barreto de. História da educação física no Brasil: currículo e formação superior. Campo Grande: Ed. UFMS, 2013. BENITES, Larissa; SOUZA NETO, Samuel de; HUNGER, Dagmar. $O$ processo de constituição histórica das diretrizes curriculares na formação de professores de Educação Física. Educação e Pesquisa, São Paulo, v.34, n.2, maio/ago. 2008, p. 343-360. BRITO NETO, Aníbal Correia. O impacto das Diretrizes Curriculares Nacionais nos Projetos Políticos Pedagógicos dos cursos de graduação em educação física do Estado do Pará. Dissertação (Mestrado em Educação), Belém: UEPA, 2009. 
A partir de 1964, o Brasil inicia um processo de ditadura militar, que iria influenciar diversos setores da sociedade, incluindo-se a educação. A Resolução de 69, à $\mathrm{EF}$, embora inicie o convívio com tendências críticas de currículo e educação, prioriza a tendência tecnicista e eminentemente prática. Os conhecimentos estavam compartimentalizados, atendendo a um modelo curricular tradicional, preocupado com o que ensinar, de forma técnica, à docência continua sendo identitária ao campo da EF, no sentido de que professores e técnicos desportivos precisavam realizar as matérias comuns - básicas e profissionais, sendo que nestas estavam as matérias pedagógicas (ABREU, 2016).

Em relação à formação, interpreta-se que a prioridade está no saber fazer, ou seja, os conhecimentos precisavam gerar resultados céleres, sendo uma ideia de formação aplicativa, pragmática e açodada. Essa ideia de formação está articulada com a teoria do capital humano, que, segundo Frigotto (2018) reduz a prática e a educação a um fator técnico de produção, aliada aos interesses do capital.

Com incentivo à pós-graduação é promulgada Resolução no 03, de 16 de junho de 1987, fixando os conteúdos e a duração mínimos dos cursos de graduação (bacharelado e/ou licenciatura plena), redimensionando o campo da $\mathrm{EF}$, no qual "a formação dos profissionais de Educação Física será feita em curso de graduação que conferirá o título de Bacharel e/ou Licenciado em Educação Física" (BRASIL, 1987, p. 01).

As legislações anteriores contribuíram, em certa medida, para que agentes do campo da EF compactuassem com a ideia fragmentária de curso, apoiando a divisão entre licenciatura e bacharelado. Pode-se inferir que há um processo histórico de institucionalização formal de habitus ${ }^{6}$, que influencia parte dos agentes constituintes do campo, no sentido de admitirem, de maneira pré-reflexiva (LUGLI, 2009), a possibilidade de fracionamento da educação física.

A Resolução 07, de 31 de março de 2004, que instituiu as Diretrizes Curriculares Nacionais para os cursos de graduação em Educação Física em nível superior de graduação plena, pauta o embate políticoacadêmico entre projetos antagônicos.

60 texto considera as maneiras, atitudes, valores, internalizadas pelos agentes, a partir da exposição longa a um processo. Para análise aprofundada, ver Bourdieu (1989). Para Bourdieu (2013, p. 57), habitus se constitui como "sistema de disposições duráveis e transponíveis que, integrando todas as experiências passadas, funciona a cada momento como uma matriz de percepções, de apreciações e de ações". Portanto, habitus requer um tempo de formação, de engendramento, de incorporação, de internalização, que faz com que os agentes respondam às diversas situações (AUTOR, 2016).
O contexto brasileiro antecessor à época de implantação da Resolução 07/2004, já havia transitado pela reformulação da Lei de Diretrizes e Bases da Educação Nacional (LDBEN 9394/96), pela recriação do Conselho Nacional de Educação (CNE), pela reestruturação do Instituto Nacional de Estudos e Pesquisas Educacionais (INEP), para organizarem as inúmeras reformas educacionais, orientadas pela presença dos organismos internacionais e de interesses privativos, inclusive por agentes formados no exterior e vinculados a esses organismos, incidindo no mercado e na educação.

Diante do histórico de fragmentação currículoformativa materializada nos diferentes documentos oficiais para os cursos de educação física, que acirra a disputa por distintos projetos nesse campoe sua direção entre os grupos que o constituem, o texto admite sua filiação à formação em educação física de caráter ampliado. Compreende-se que é especialmente após a Resolução de 1987, que escancara a divisão entre licenciados e bacharéis e os condicionantes sociais reais que daí resultam, que os diferentes projetos de educação física se mostram firmemente definidos, ou como destaca Faria Júnior (1987), um projeto de formação especialista ou generalista.

Conforme analisado em Brito Neto (2009, p. 69), a formação em educação física de caráter ampliado deve tributo em grande medida "aos esforços da Linha de Estudo e Pesquisa em Educação Física \& Esporte e Lazer (LEPEL)", institucionalizada na Universidade Federal da Bahia (UFBA), e às publicações de seus integrantes. Nesse sentido, a formação em educação física é unificada na licenciatura, de forma ampliada, seja na formação/investigação, seja no trabalho desse profissional docente. Essa formação compreende a defesa de uma formação humana em suas múltiplas dimensões, integral, generalista, conforme Quelhas; Nozaki (2018), que ressaltam que esta formação "deve formar o aluno não apenas para lecionar tecnicamente os conteúdos, mas para articular os conteúdos na perspectiva da totalidade e no empenho da própria formulação de políticas educacionais da área" (Ibid, p. 39), o que indica possibilidades de realização de um ensinoaprendizagem (formação, currículo) para a libertação e emancipação e, à autonomia e desenvolvimento da profissionalidade docente.

No entanto, a formação ampliada e única na educação física brasileira encontra resistência ante um grupo de agentes, como o sistema CONFEF/ CREF que tem uma posição política e um projeto de educação física fragmentário, utilizando a legislação e o mercado para agir com ilicitudes no campo. 


\section{A DISPUTA ENTRE PROJETOS DE FORMAÇÃO NA EDUCAÇÃO FÍSICA}

As Diretrizes Curriculares Nacionais para a formação de professores de Educação Física no Brasil, homologadas pela Resolução 6/2018- CNE/MEC, tem como marco o conteúdo explícito no inciso XXIV, do Art. 22, da Constituição Federal, a qual estabelece a competência privativa da União para legislar sobre as diretrizes e bases da educação nacional (BRASIL, 2016).

Com a aprovação da Lei no 9.131, de 24 de novembro de 1995, se define o Conselho Nacional de Educação (CNE), como estrutura pertencente ao Ministério da Educação, em que ficou estipulado a este, dentre outras atribuições, conforme Art. 70: “d) emitir parecer sobre assuntos da área educacional, por iniciativa de seus conselheiros ou quando solicitado pelo Ministro de Estado da Educação e do Desporto; f) analisar e emitir parecer sobre questões relativas à aplicação da legislação educacional, no que diz respeito à integração entre os diferentes níveis e modalidade de ensino" (BRASIL, 1995, p. 01).

Cabe à Câmara de Educação Superior deste órgão, dentre outras atribuições: “Art. 9으, $§ 2$, c) deliberar sobre as diretrizes curriculares propostas pelo Ministério da Educação e do Desporto, para os cursos de graduação; h) analisar questões relativas à aplicação da legislação referente à educação superior" (BRASIL, 1995, p. 01).

De igual forma, essa base legal foi mantida na Lei no 9.394, de 20 de dezembro de 1996 (LDBEN), de modo que, considerando a base legal para deliberar sobre diretrizes curriculares, a Câmara de Educação Superior do CNE, a partir do Parecer CNE no 776, de 3 de dezembro de 1997, definiu orientações para a elaboração das novas diretrizes curriculares para os cursos de graduação.

Nessa perspectiva, à luz da compreensão entre formação profissional e diplomação expresso por meio do Art. 48 LDBEN 9394/96, em que se atestou o diploma como "[...] prova de formação recebido por seu titular" (BRASIL, 1996, p. 01), a defesa expressa por meio do Parecer CNE no 776/97 acerca dos currículos dos cursos de graduação caminhou em direção ao abandono da tradição de se estabelecer um "currículo mínimo", por desencorajar a inovação e a diversificação da formação.

Desta feita, com a publicação do Edital da Secretaria de Educação Superior do MEC, no 4, de 10 de dezembro de 1997, ficou aberta a composição de Comissões de Especialistas como órgão auxiliar da Câmara de Educação Superior (CES) do CNE no processo de elaboração de novas Diretrizes Curriculares para os cursos de graduação. Ao findar os trabalhos das
Comissões de Especialistas e sem consenso na área sobre o texto construído como proposta para as novas DCN em substituição a base legal de 1987, foi aprovada a Resolução CNE/CES no 7/04..

Apesar da compreensão geral por parte do CNE de que a formação em EF para a Licenciatura deveria considerar o conteúdo estabelecido na Resolução CNE/ CES no 7/04 adicionada do conteúdo da Resolução CNE/ CP no 1, de 18 de fevereiro de 2002, e a formação em EF para o Bacharelado apenas o conteúdo da primeira, criou-se na área uma falsa verdade de que a Resolução CNE/CES no 7/04 guardava as diretrizes apenas para os cursos de Bacharelado e, a Resolução CNE/CP no $1 / 02$, que trata das Diretrizes Curriculares Nacionais para a Formação de Professores da Educação Básica, o conteúdo para os cursos de Licenciatura em EF.

O Parecer CNE/CES no 400, de 24 de novembro de 2005, configura-se como importante peça jurídica do processo de implementação das novas DCN para os Cursos de Graduação em EF, nas modalidades Licenciatura e Bacharelado.

Desta forma, não tem sustentação legal - e mais, é flagrantemente inconstitucional - a discriminação do registro profissional e, portanto, a aplicação de restrições distintas ao exercício profissional de graduados em diferentes cursos de graduação de Licenciatura ou de Bacharelado em Educação Física, através de decisões de Conselhos Regionais ou do Conselho Federal de Educação Física. Portanto, a delimitação de campos de atuação profissional em função da modalidade de formação, introduzida pelo artigo 3o da citada Resolução CONFEF no 94/2005, assim como as eventuais restrições dela decorrentes, que venham a ser aplicadas pelos Conselhos Regionais de Educação Física, estão em conflito com o ordenamento legal vigente no país. (BRASIL, 2005, p. 4-5).

Esse raciocínio assenta-se no fato de que inexiste no ordenamento jurídico brasileiro qualquer lei que proíba o licenciado em EF de atuar nos espaços não-escolares, ou seja, em clubes, academias de ginástica, clínicas, hospitais, hotéis e parques, ou ainda em empresas que demandem sua formação específica e em instituições que desenvolvem pesquisas educacionais.

Quando o CNE foi convidado a se manifestar acerca das DCN dos Cursos de Graduação em EF, o conteúdo dos Pareceres e Ofícios exarados caminham em consonância com a íntegra do Parecer CNE/CES no 400/05. Dessa forma, visualiza-se no Parecer CNE/CES no 274/11, de 6 de julho de 2011, dos conselheiros Paulo Barone e Maria Beatriz Luce, que a interpretação 
equivocada da Resolução CNE/CES no 7/04 se configura como uma ação negligente e tem sido utilizada, principalmente pelo órgão de classe (CONFEF), como instrumento para impedir o livre exercício da profissão pelos Licenciados em EF nos campos não-escolares, quando não ficou instituído, em qualquer normativa legal, esse expresso e inequívoco impedimento.

Ambos os títulos (Bacharel ou Licenciado) requerem uma formação acadêmica com conteúdo comum referente ao campo da Educação Física. O comando curricular é único e indissociável. A única diferença está no fato de que a formação dos Licenciados em Educação Física, além de atender à Resolução CNE/ CES no 7/2004, deve também atender ao disposto na Resolução CNE/CP no 1/2002, que institui Diretrizes Curriculares Nacionais para a Formação de Professores da Educação Básica, em nível superior, curso de licenciatura de graduação plena. [...]

Resulta da consideração destes dispositivos que é competência legal da Câmara de Educação Superior deste Conselho deliberar sobre as Diretrizes Curriculares e interpretá-las. Em decorrência disso, apenas a Câmara tem legitimidade para reafirmar o seu conteúdo. Dessa forma, é importante registrar que não há no Parecer CNE/CES n. 58/2004, na Resolução CNE/CES n. 7/2004, nem em qualquer outra manifestação deste Conselho, indicativo da possibilidade de interpretar que a formação em Educação Física tenha natureza distinta daquela que está definida por estes documentos normativos. As Diretrizes Curriculares Nacionais para os cursos de graduação em Educação Física são únicas, e qualquer outra interpretação é imprópria. Os conteúdos curriculares, assim como as competências e habilidades previstas nas Diretrizes, referentes ao campo técnico-científico da Educação Física, são idênticas para a licenciatura e o bacharelado, não havendo divisão possível para nenhum efeito. Mais uma vez, deve ser ressaltado que a licenciatura requer competências adicionais, nos termos da já citada Resolução CNE/CP no 1/2002 (BRASIL, 2011a, p. 5-6).

Além das análises e interpretações realizadas pelo CNE acerca das DCN dos Cursos de Graduação em EF, a SESU/MEC publicou, em abril de 2010, documento intitulado "Referenciais Curriculares Nacionais dos Cursos de Bacharelado e Licenciatura". Neste é explicitado o perfil do egresso, os temas abordados na formação, os ambientes de atuação e a infraestrutura recomendada.
Ao tratar dos Cursos de Bacharelado e de Licenciatura em EF, há uma repetição acerca dos temas abordados na formação, para ambos os cursos, com acréscimos para a Licenciatura, assim como no quesito ambientes de atuação, repetem-se os espaços de educação não-formal para ambos os cursos e se acrescenta, para a Licenciatura, as instituições de ensino da educação básica. Portanto, há o reconhecimento da ampla intervenção do Licenciado em EF por meio de documentos oficiais do MEC.

Frente ao que se coloca, o diálogo é franqueado entre a comunidade científica, os legisladores e os professores, por meio de diferentes espaços de discussão e produção, a exemplo do Fórum de Licenciatura Ampliada, do Movimento Nacional contra a Regulamentação - MNCR, do Grupo de Trabalho Temático (GTT) Formação Profissional e Mundo do Trabalho/CBCE e dos grupos de pesquisa defensores da formação ampla.

O GTT Formação Profissional e Mundo do Trabalho do Colégio Brasileiro de Ciências do Esporte (CBCE), manifestou posição junto ao Conselho Nacional de Educação (CNE) endereçando a Comissão de Especialistas, carta sobre o processo de reformulação das DCN onde se lê que:

O GTT Formação Profissional e Mundo do Trabalho que, desde sua criação desempenha papel importante no que diz respeito à produção acadêmico-científica da $E F$, vem expor seus argumentos e posicionamentos sobre a Minuta de Projeto de Resolução apresentada no dia 11 de dezembro de 2015 em Brasília-DF que trata das DCN para o curso de graduação em EF, com formação única pela licenciatura.

Diante deste contexto este GTT apresenta o posicionamento pautado na posição histórica construída ao longo dos 39 anos de criação e nos quais promove estudos e investigações quanto às implicações das mudanças legais promovidas pela Resolução CNE 07/2004 para a formação profissional e mundo do trabalho nos CONBRACES/CONICES e nos eventos regionais realizados nos anos pares, em todas as regiões do país. A defesa pela licenciatura com caráter ampliado materializou articulação com o Fórum das Licenciaturas com Formação Ampliada, participando de atividades que mereceram discussões e posicionamentos, nos encontros em São Luís- MA em 2012 (SBPC), Goiânia-GO em dezembro de 2012, Brasília-DF em 2013, Salvador-BA em setembro de 2013. Neste sentido, o GTT Formação Profissional e Mundo do Trabalho, nesta gestão 2015-2017 
e aportado na história e produção acadêmicocientífica da área ratifica o posicionamento em favor da formação única, tal como vem preconizando a proposta atual do Conselho Nacional de Educação (GTT FORMAÇÃO, 2017, p. 3-5).

Assim como o GTT Formação/CBCE, grupos de pesquisa de incisiva participação no debate sobre a formação de professores, têm se posicionado publicamente e elaborado documentação a favor da licenciatura ampliada. Entre os grupos de pesquisa, foi encaminhado ao CNE proposta de minuta de Resolução que trata essencialmente da formação unificada e contempla:

A formação em Educação Física, para atuar nos campos de intervenção citados no caput do Art. 9으, deverá contemplar os seguintes eixos articuladores: I - Saúde: políticas e programas de saúde; atenção básica, secundária e terciária em saúde, saúde coletiva, Sistema Único de Saúde, dimensões e implicações biológica, psicológica, sociológica, cultural e da saúde; integração ensino, serviço e comunidade; gestão em saúde; objetivos, conteúdos, métodos e avaliação de projetos e programas de Educação Física na saúde; II Esporte: políticas e programas de esporte; treinamento esportivo; dimensões e implicações biológica, psicológica, sociológica, cultural e pedagógica do esporte; gestão do esporte; objetivos, conteúdos, métodoseavaliação de projetose programas deesporte; III - Cultura e lazer: políticas e programas de cultura e de lazer; gestão de cultura e de lazer; dimensões e implicações biológica, psicológica, sociológica, cultural e pedagógica do lazer; objetivos, conteúdos, métodos e avaliação de projetos e programas de Educação Física na cultura e no lazer (RESSIGNIFICAR, 2017).

Todo esse aparato teórico e apreciação do estágio atual das DCN, pode ser localizado nos sítios das associações científicas na área e dos grupos de pesquisa que estão à frente do embate fundamentado em favor da formação unificada em EF. Esse esforço coletivo de pesquisa e estudos, cientificamente fundamentados, qualificam e representam o debate e a produção na área da $E F$, sustentando a defesa na formação única e ampliada.

Em último ato legal, a CES/CNE/MEC - Câmara de Ensino Superior institui as novas DCN sob a Resolução no 6, de 18 de dezembro de 2018, publicada no Diário Oficial da União (DOU no 243, 19.12.2018, Seção 1, p. 48 e 49), o que mobiliza a comunidade acadêmicocientífica e convoca para estudo e análise desse ordenamento para a formação em EF.
Mesmo sabendo que houve um esforço coletivo e aproximação com os grupos de pesquisa, associações e conselhos, o texto final da Res. 6/2018, foge ao discutido e proposto no processo de construção que incluiu audiências públicas, colaborações propositivas no formato minuta, diálogos interinstitucionais e com - CNE/MEC. Ainda há lacunas e imprecisões legais que implicam na ação formadora e na intervenção profissional. A saber:

Art. 5o Dada a necessária articulação entre conhecimentos, habilidades, sensibilidade e atitudes requerida do egresso para o futuro exercício profissional, a formação do graduado em Educação Física terá ingresso único, destinado tanto ao bacharelado quanto à licenciatura, e desdobrar-se-á em duas etapas, conforme descrição a seguir: I- Etapa Comum - Núcleo de estudos da formação geral, identificador da área de Educação Física, a ser desenvolvido em 1.600 (mil e seiscentas) horas referenciais, comum a ambas as formações. II - Etapa Específica - Formação específica a ser desenvolvida em 1.600 (mil e seiscentas) horas referenciais, na qual os graduandos terão acesso a conhecimentos específicos das opções em bacharelado ou licenciatura (BRASIL, 2018, p. 48).

É fato que sendo o objeto de estudo da área da EF, as práticas corporais ${ }^{7}$ tematizadas nas manifestações do jogo, da ginástica, da dança, do esporte, das lutas e da capoeira, eminentemente da cultura brasileira, todo o acervo teórico-conceitual é voltado para a compreensão da área e independe do campo de atuação. $O$ que difere é a forma, isto é, a metodologia e acessórios didático-pedagógicos. Portanto, esse Art. 5o merece estudo cuidadoso, técnico e acadêmico sobre as dimensões do conhecimento nas Etapa I e II.

Discorrer sobre o texto da Res. 6/2018 é identificar outros aspectos que concorrem para uma formação mais técnica do que acadêmica, e numa formação fragmentada quanto ao domínio dos fundamentos da EF como área de conhecimento que se explica e se exerce no diálogo entre as Ciências Naturais e as Ciências Sociais e Humanas.

Como executar uma Resolução que se contradiz entre um artigo e outro, quando nos deparamos com o texto

7 Tudo aquilo que foi produzido e sistematizado pela humanidade em nível de jogos, esportes, lutas, danças e ginásticas e que busca a formação humana nessas temáticas. Essa concepção de objeto de investigação na Educação Física é defendida pelo Projeto Político Pedagógico (PPP) do curso de graduação em educação física da Universidade do Estado do Pará (UEPA). Disponível em https://paginas.uepa.br/ccbs/edfisica/files/PPP_UEPA.pdf Acesso em outubro de 2019. 
Art. 10 O Licenciado em Educação Física terá formação humanista, técnica, crítica, reflexiva e ética qualificadora da intervenção profissional fundamentada no rigor científico, na reflexão filosófica e na conduta ética no magistério, ou seja, na docência do componente curricular Educação Física, tendo como referência a legislação própria do Conselho Nacional de Educação para a área. Art. 11 As atividades práticas da etapa específica da Licenciatura deverão conter o estágio supervisionado, bem como outras vinculadas aos diversos ambientes de aprendizado escolares e não escolares (BRASIL, 2018, p. 48. Grifos nossos).

Ora, se no texto da Resolução como um todo o Licenciado estará apto a docência e ao trabalho na escola, a Resolução em tela dá margem para dúbia interpretação quando refere ao campo não escolar como campo de estágio. A continuidade da análise identifica outras contradições, que pouco concorrem para dirimir os obstáculos epistemológicos da área e mais ainda, o imbróglio legal para o exercício da profissão de professor de EF.

E por fim, desses estudos iniciais das novas DCN para a EF, tem-se que Art. 20 A formação do Bacharel em Educação Física, para atuar nos campos de intervenção citados no caput do Art. 10, deverá contemplar os seguintes eixos articuladores: I - saúde: políticas e programas de saúde; atenção básica, secundária e terciária em saúde, saúde coletiva, Sistema Único de Saúde, dimensões e implicações biológica, psicológica, sociológica, cultural e pedagógica da saúde; integração ensino, serviço e comunidade; gestão em saúde; objetivos, conteúdos, métodos e avaliação de projetos e programas de Educação Física na saúde; II - esporte: políticas e programas de esporte; treinamento esportivo; dimensões e implicações biológica, psicológica, sociológica, cultural e pedagógica do esporte; gestão do esporte; objetivos, conteúdos, métodos e avaliação de projetos e programas de esporte; e III - cultura e lazer: políticas e programas de cultura e de lazer; gestão de cultura e de lazer; dimensões e implicações biológica, psicológica, sociológica, cultural e pedagógica do lazer; objetivos, conteúdos, métodos e avaliação de projetos e programas de Educação Física na cultura e no lazer (BRASIL, 2018, p. 48. Grifos nossos).

Há uma incorreção do Art. 20 que trata do Bacharel ao remeter ao Art. 10 que refere ao Licenciado, ao mesmo tempo, que as competências para as atividades listadas nos dois artigos desconsideram a natureza das subáreas da EF quando essas se interseccionam na dimensão pedagógica, o que ratifica que a $E F$ como campo de conhecimento é única e que em sua intervenção profissional devem ser consideradas o domínio de conteúdo e a apropriação técnica.

Ademais, é importante frisar que a legislação $6 / 2018$, interpõe-se ao debate coletivo sobre as DCN, retratando desconsideração aos esforços legítimos de diálogo. Impera, portanto, a hegemonia de vozes alheias aos âmbitos formativo e de trabalho da EF, ao mesmo tempo, que não reconhece a constitucionalidade da autonomia do debate acadêmico e das universidades ${ }^{8}$, como lócus de pesquisas qualificadoras cientificamente, das problemáticas da educação física.

\section{DESAFIOS POSTOS E A ENFRENTAR}

A caracterização da Formação de Professores no Brasil é perpassada por problemas e desafios (GATTI, 2010) que, no conjunto da luta orgânica ${ }^{9}$ da classe dos professores é preciso enfrentar, com propostas construídas a partir das condições de oferecimento da formação pelas instituições de ensino superior e pelas limitações impostas pelas normativas legais.

Os problemas anunciados pela autora citada incluem a falta de base sólida de formação e as formas de ação docente. No entanto,

Há muitos modos do fazer a ação do ensinaraprender que vão desde a ação prática do cotidiano no ambiente educativo até a cientifização por meio de teorias do conhecimento, teorias da educação e teorias pedagógicas. Essa é a construção histórica e sistematizada para a escolarização dos saberes e construção do conhecimento (GENú, 2016, p. 1).

O modus operandi docente aciona uma cultura científica que perpassa pela experiência e vivência acumuladas pelos anos de docência e vida com as práticas educativas. Para aqueles que convivem com os pares e acessam uma formação para além da inicial, ainda é possível enfrentar os desafios postos e os vindouros. Ainda é Gatti (2010) quem elenca os desafios como a necessária reformulação das estruturas institucionais e dos currículos de formação inicial, colocados como questões para o enfrentamento que sinaliza estratégias de superação.

A superação é indicada num conjunto de mudanças de atitude e fazeres, com: o protagonismo docente, a articulação sociopolítica do professor, a valorização do conhecimento profissional do professor, e a reconstrução do espaço acadêmico, para uma revolução no campo da formação de professores, como apontado por Nóvoa (2013).

8 Art. 207ํ da Constituição Brasileira (BRASIL, 2016).

$9 \mathrm{Em}$ referência à luta dos profissionais que conscientes da relevância da educação física como potencial para a formação humana, reivindicam o acervo e o acesso plenos das práticas corporais. 
Na concepção da formação unificada se tem a licenciatura de caráter ampliado, com o trabalho como princípio educativo, a teoria do conhecimento sustentada pela história, a educação na perspectiva crítica e as práticas corporais historicamente sistematizadas e construídas na cultura.

Outra posição de enfrentamento para superação é argumentar em base sólida, isto é, dos próprios projetos pedagógicos dos cursos (PPC) nas instituições que ofertam as modalidades licenciatura e bacharelado e naquelas que assumem o caráter ampliado da licenciatura. Em todas elas os PPC guardam similaridades na oferta do conhecimento, e em algumas superam os critérios e as normas emanados da legislação vigente, importando para elas a sólida formação promovida pelo conjunto de conhecimentos que abarcam as disciplinas que transversalizam e tratam do objeto de estudo da $\mathrm{EF}$, as práticas corporais.

Frente a homologação da Res. 06/2018, a apreciação do caput de artigos específicos reporta aos limites impostos por esse ordenamento, e que deverão ser superados pela comunidade, que ainda se organiza por diferentes projetos políticos de formação. Essa legislação, ao fragmentar e estar alinhado a um conjunto de dispositivos legais, como a Base Nacional Comum Curricular (BNCC), sustentada na competência, que por suavez, tem relação direta com o mercado e com o capital, busca desenvolver uma espécie de habitus produtivus, ou seja, submeter os agentes a um longo processo de práticas formativas competentes, mercadológicas, buscando com que estes percebam, apreciem e produzam atitudes nesse viés; ao internalizarem essas práticas formativas, as matrizes de percepção, apreciação e ação dos agentes, têm a possibilidade de reforçarem essa formação, dada a incorporação dessas práticas e as condições de sua reprodução $0^{10}$.

Essa normativa legal, ao gerar esses desafios ao campo da educação física, apresenta um descompromisso com a própria profissionalidade docente nesse campo, pois reforça a separação entre os grupos e acirra as lutas entre eles mesmos - pelo trabalho, pela formação, pelo significado de educação física, pelo poder de decisão, pelo sentido de pertença a esse coletivo, como se viu em Roldão (2005) -, perdendo o sentido de luta pela educação física em sua totalidade, ante o campo do poder.

A ação imediata é a de apropriação da conjuntura política e para a educação em todos os níveis, com o estudo amiúde mais célere, em nome do processo humanizador, com respeito aos direitos conquistados

10 Não necessariamente o habitus gera práticas de manutenção das estruturas; as práticas dos agentes podem ser de subversão das estruturas. Cf: BOURDIEU, Pierre. Esboço de uma teoria prática. In: ORTIZ, Renato. (org.). A sociologia de Pierre Bourdieu. São Paulo: Olho d'água, 2013, p. 39-72. na trajetória histórica e de luta democrática, em que a autonomia das agências formadoras, garantida pela constituição brasileira se mantenha em respeito aos professores adeptos do projeto de formação humana com competência técnica e compromisso político.

Cada uma dessas mudanças/ações requer uma apreciação, a exemplo das formações de base que têm sido feitas nas diversas universidades, como necessárias para o embate, visto que solidifica o núcleo estruturante do campo e, consequentemente da formação e do trabalho docente (ação política e pedagógica), salvaguardando o protagonismo e autonomia das IES e da comunidade docente, que têm como suporte os estudos e pesquisas sobre formação do professor, desde autores que circulam na grande área da Educação aos estudiosos que compartilham o cotidiano dos (as) professores/as.

\section{REFERÊNCIAS}

GENÚ, Marta. Escritos Freireanos Sobre Formação do Professor: A Construção Contínua da Ação Docente nas Experiências Latino Americanas. Revista Cocar, v. n 2, p. 207-225, 2016.

ABREU, Meriane. Praxiologia em Bourdieu: análise entre o campo científico e o currículo da educação física. Dissertação (Mestrado em Educação), Belém: UEPA, 2016.

AZEVEDO, Ângela Celeste Barreto de. História da educação física no Brasil: currículo e formação superior. Campo Grande: Ed. UFMS, 2013.

BARDIN, Laurence. Análise de conteúdo. Tradução Luís Antero Reto; Augusto Pinheiro. São Paulo: Edições 70, 2011.

BENITES, Larissa; SOUZA NETO, Samuel de; HUNGER, Dagmar. O processo de constituição histórica das diretrizes curriculares na formação de professores de Educação Física. Educação e Pesquisa, São Paulo, v.34, n.2, maio/ago. 2008, p. 343-360.

BOURDIEU, Pierre. O poder simbólico. Lisboa: DIFEL, 1989.

BOURDIEU, Pierre. A distinção: crítica social do julgamento. Tradução Daniela Kern; Guilherme J. F. Teixeira. São Paulo: EDUSP; Parto Alegre, RS: Zouk, 2007.

BOURDIEU, Pierre. Esboço de uma teoria prática. In: ORTIZ, Renato. (org.). A sociologia de Pierre Bourdieu. São Paulo: Olho d'água, 2013, p. 39-72.

BRASIL. Constituição da República Federativa do Brasil: texto constitucional promulgado em 5 de outubro de 1988, com alterações determinadas pelas Emendas Constitucionais de Revisão nos 1 a 6/94, pelas Emendas Constitucionais nos $1 / 92$ a 95/2016 e pelo Decreto Legislativo no 186/2008. Brasília: Senado Federal, Coordenação de Edições Técnicas, 2016. 510 p.

BRASIL. Decreto-Lei no 1212, de 17 de abril de 1939. Dispõe sobre organização do conhecimento na formação. Disponível em: http://www2.camara.leg.br/legin/fed/ declei/1930-1939/decreto-lei-1212-17-abril-1939-349332publicacaooriginal-1-pe.html. Acesso em: dez. 2015.

BRASIL. Lei № 9.131, de 24 de novembro de 1995. Disponível em https://www.camara.leg.br/sileg/integras/408236.pdf. Altera dispositivos da Lei no 4.024, de 20 de dezembro de 1961, e dá outras providências. Acesso em dez. 2015

BRASIL. Lei de Diretrizes e B. Lei no 9.394/96, de 20 de dezembro de 1996. Ministério da Educação e do Desporto, Secretaria de Educação Fundamental. Estabelece as diretrizes e bases da educação nacional. Disponível em http://www.planalto. gov.br/ccivil_03/leis/19394.htm. Acesso em dez. 2015 
BRASIL. Resolução CFE 69/69. Trata dos modelos curriculares para a formação em Educação Física. Disponível em: http:// cev.org.br/biblioteca/parecer-69-69/. Acesso em: jan. 2016.

BRASIL. Resolução CFE no 03, de 16 de junho de 1987. Resolve a distribuição do conhecimento na formação. Disponível em: http://www.ufpb.br/sods/consepe/resolu/1990/Res0387cfe.htm. Acesso em: jan. 2016.

BRASIL. Resolução no 07, de 31 de março de 2004. Trata da organização curricular para graduação em Educação Física. Disponível em: http://portal.mec.gov.br/cne/arquivos/pdf/ ces0704edfisica.pdf. Acesso em: jan. 2016.

BRASIL. Resolução no 06, de 18 de dezembro de 2018. Revoga a Resolução 07/2004 e dá nova organização a Graduação em Educação Física. Disponível em http://portal.mec.gov. $\mathrm{br} /$ index.php?option=com_docman\&view=download\&al ias=104241-rces006-18\&category_slug=dezembro-2018pdf\&Itemid=30192. Acesso em jan. 2019.

BRITO NETO, Aníbal Correia. O impacto das Diretrizes Curriculares Nacionais nos Projetos Políticos Pedagógicos dos cursos de graduação em educação física do Estado do Pará. Dissertação (Mestrado em Educação), Belém: UEPA, 2009.

EVANGELISTA, Olinda. TRICHES, Jocemara. Professor (a): a profissão que pode mudar um país? Revista HISTEBR Online, [S.I.], v. 15, n. 65, p. 178-200, dez. 2015.

FARIA JUNIOR, Alfredo G. Professor de educação física, licenciado generalista. In: OLIVEIRA, Vitor Marinho (Org.). Fundamentos Pedagógicos Educação Física: flexões e reflexões. Rio de Janeiro: Ao Livro Técnico, 1987.

FREIRE, Paulo. SHOR, Ira. Medo e Ousadia. O Cotidiano do Professor. Rio de Janeiro: Paz e Terra, 1986.

FREIRE, Paulo. Pedagogia da autonomia: saberes necessários à prática educativa. São Paulo: Paz e Terra, 1996.

FREIRE, Paulo. Pedagogia do oprimido. 50. ed. rev. e atual. Rio de Janeiro: Paz e Terra, 2011.

FRIGOTTO, Gaudêncio. A produtividade da escola improdutiva: um (re) exame das relações entre educação e estrutura econômico-social e capitalista. 8 ed. São Paulo: Cortez, 2018.
GAMBOA, Silvio Sánchez. Quantidade-qualidade: para além de um dualismo técnico e de uma dicotomia epistemológica. In: SANTOS FILHO, José Camilo dos; GAMBOA, Silvio Sánchez (orgs.). Pesquisa educacional: quantidade-qualidade. 8 ed. São Paulo: Cortez, 2013, p. 83-108.

GATTI, Bernadete A. Formação de professores no Brasil: características e problemas. In: Educação \& Sociedade, Campinas, v. 31, n. 113, p. 1355-1379, out. - dez. 2010

RESSIGNIFICAR/UEPA. Minuta de Resolução para formação em Educação Física. Belém, 2017 (digitalizado).

GTT FORMAÇÃO. Minuta de Resolução para formação em Educação Física. Belém, 2017 (digitalizado).

LUGLI, Rosário Genta. Pensadores da educação Pierre Bourdieu. Belo Horizonte. Produzido por ATTA Mídia e Educação, encomendado por La Guardia Digital Ltda. Licenciado e distribuído por Centro Difusor de Cultura LTDA - CEDIC, 2009. DVD (33 minutos).

NÓVOA, Antonio. Nada substitui um bom professor: propostas para uma revolução no campo da formação de professores. In: GATTI, Bernadete Angelina et al (org.). Por uma política nacional de formação de professores. São Paulo: Editora Unesp, 2013.

QUELHAS, Álvaro de Azeredo; NOZAKI, Hajime Takeuchi. A licenciatura ampliada no contexto dos projetos de formação humana em disputa na educação física brasileira. In: ALMEIDA, Paulo Antônio Cresciulo de; CASTRO, Waldyr Lins de. (Orgs.). A licenciatura em educação física na UFF: uma alternativa curricular. Curitiba: CRV, 2018, p. 29-45.

ROLDÃO, Maria do Céu Neves. Profissionalidade docente em análise especificidades dos ensinos superior e não superior. Nuances: estudos sobre educação-ano XI, v. 12, n. 13, jan./dez. 2005, p. 105-126.

SOUZA JÚNIOR, Marcílio et al (2011). Coletivo de autores: a cultura corporalemquestão.Disponívelem:http://www.scielo.br/scielo. php?script=sci_arttext\&pid=S0101-32892011000200008. Acesso em: nov. 2014.

TRIVIÑOS, Augusto Nibaldo Silva. Introdução à pesquisa em ciências sociais: a pesquisa qualitativa em educação. 1 ed. 21 reimpr. São Paulo: Atlas, 2012. 